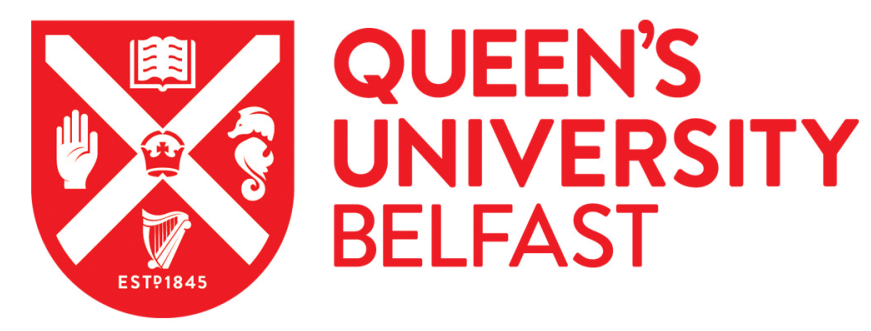

\title{
Adapting the FlexiArch for widening a complex arch bridge
}

Long, A., Gupta, A., McPolin, D., \& Cook, J. (2018). Adapting the FlexiArch for widening a complex arch bridge. Proceedings of ICE - Bridge Engineering, [1700007].

Published in:

Proceedings of ICE - Bridge Engineering

Document Version:

Peer reviewed version

Queen's University Belfast - Research Portal:

Link to publication record in Queen's University Belfast Research Portal

Publisher rights

(C) 2018 ICE Publishing.

This work is made available online in accordance with the publisher's policies. Please refer to any applicable terms of use of the publisher.

\section{General rights}

Copyright for the publications made accessible via the Queen's University Belfast Research Portal is retained by the author(s) and / or other copyright owners and it is a condition of accessing these publications that users recognise and abide by the legal requirements associated with these rights.

Take down policy

The Research Portal is Queen's institutional repository that provides access to Queen's research output. Every effort has been made to ensure that content in the Research Portal does not infringe any person's rights, or applicable UK laws. If you discover content in the Research Portal that you believe breaches copyright or violates any law, please contact openaccess@qub.ac.uk. 


\section{ADAPTING THE FLEXIARCH FOR WIDENING A COMPLEX ARCH BRIDGE}

Adrian Long OBE, FREng PhD, DSc, FICE, FIStructE, Queen's University Belfast, Belfast, UK

Abhey Gupta BTech, MTech, MPhil, Macrete Ireland Ltd, Toomebridge, UK

Daniel McPolin BEng, MSc, PhD, Queen's University Belfast, UK

John Cook MEng, MSc, WSP, Bristol, UK

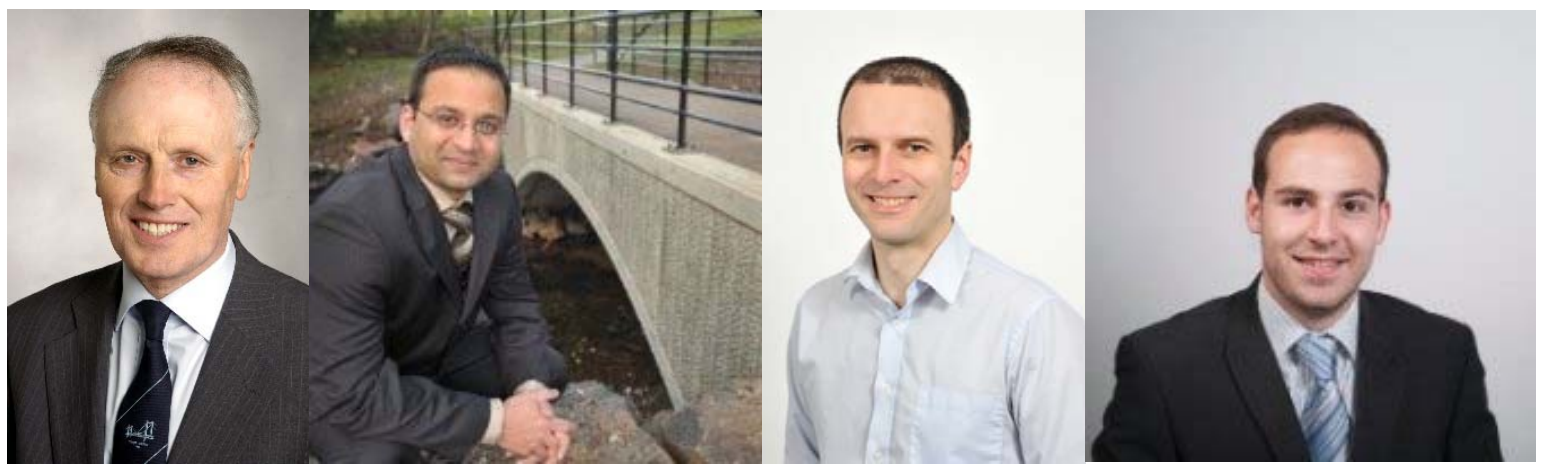

\section{Abstract}

The 1840's Teewell Hill arch bridge, in the suburbs of Bristol, was no longer adequate for increasing local traffic levels and needed to be widened. Several widening options were considered and it was concluded that the innovative FlexiArch would best accommodate the complex geometry of the existing structure whilst minimising social and economic impacts. In order to elegantly accommodate the raked spandrel walls of the existing bridge Macrete and WSP | Parsons Brinckerhoff worked collaboratively to produce a custom designed high quality precast concrete 'FlexiArch' which matched the contours of the existing bridge. As the FlexiArch system has no corrodible reinforcement, it is highly sustainable and will result in reduced maintenance as for the existing bridge. The elimination of centring and speed of construction (hours not months) minimised disruption to road traffic and to cyclists on the cycle network below the bridge - a key project criterion required by the client. Thus, in addition to addressing an accident black spot, the FlexiArch solution provided South Gloucestershire Council (the client) with an aesthetically pleasing and fully functional solution at a competitive cost.

\section{Introduction}

Teewell Hill arch bridge, located in the Staple Hill area of Bristol and constructed in the 1840's required widening in order to enhance the safety of road traffic users and provide an improved carriageway alignment. This aesthetically pleasing bridge carries a busy road and spans a National Cycle route. An assessment had concluded that the existing masonry bridge was able to sustain SV loading and as a result, South Gloucestershire Council were keen that a widening scheme which retained an aesthetically pleasing arch form of construction was developed. However, traditional masonry arches are notoriously slow to build and the centring would have resulted in closure of the cycle route below the bridge throughout the arch construction.

The consultant, WSP | Parsons Brinckerhoff who had previous experience of using the FlexiArch system suggested that it could possibly be adapted to address the geometrical constraints of the existing bridge. At this stage Macrete Ireland, who manufacture the FlexiArch, were consulted. The major challenge and one of the key design requirements to be addressed was that the raked spandrel walls and the unsymmetrical geometry of the bridge meant that the existing arch voussoir profile was 
curved in plan. Using their experience gained from developing a skew 'FlexiArch' system Macrete, in collaboration with WSP | Parsons Brickerhoff, designed and manufactured custom made FlexiArch units, with each voussoir individually tailored to match the contours of the existing arch profile. Use of these custom designed FlexiArch units resulted in multiple benefits including aesthetic qualities and durability characteristics commensurate with the existing structure.

In this paper the background concept of the FlexiArch system will be briefly described before explaining how it was adapted to solve the particular challenge associated with the widening of Teewell Hill bridge.

\section{BACKGROUND TO FLEXIARCH SYSTEM}

In the early 1990's when Gordon Millington was Vice President of the ICE he asked the first author the question, why are few if any arch bridges being built as they are aesthetically pleasing, strong, durable and require little maintenance? As explained in greater detail by Long et al (2013) this prompted research with the aim of answering this perceptive question. Beam and slab and rigid precast concrete arch bridges have been found to be vulnerable to reinforcement corrosion and some have deteriorated after only 20-30 years. In reaction to this the UK Highways Agency recommended the use of the arch form and also stated that 'consideration be given to all means of reducing or eliminating the use of corrodible reinforcement (HMSO 2004). The challenge therefore was to develop an arch system with all the attributes of an unreinforced masonry arch which:

- Can be installed as quickly as alternatives

- Eliminates the need for centring

- Uses existing methods of analysis/design

- Is cost competitive

- Uses precast concrete and is suitable for off-site construction

- Had no corrodible reinforcement

The patented 'FlexiArch' system (Long 2004) was developed in response and only a brief description of this innovative system will be given here, as the main focus of this paper is on the application to the widening of the Teewell Bridge.

\section{Method of Manufacture}

The 'FlexiArch' is constructed and transported to site in flat pack form using polymeric reinforcement to carry the self-weight of the arch unit during lifting. Once in place it behaves as a conventional masonry arch. The preferred method of construction of the arch unit is shown in Fig 1 (more detail in Long et al 2013). For the manufacture of each arch unit the tapered voussoirs are precast individually then they are laid contiguously with the top edge touching, in a horizontal line with a layer of polymeric reinforcement placed on top. In-situ screed, approximately $40 \mathrm{~mm}$ thick, is placed on top and allowed to harden so that the voussoirs are interconnected. 

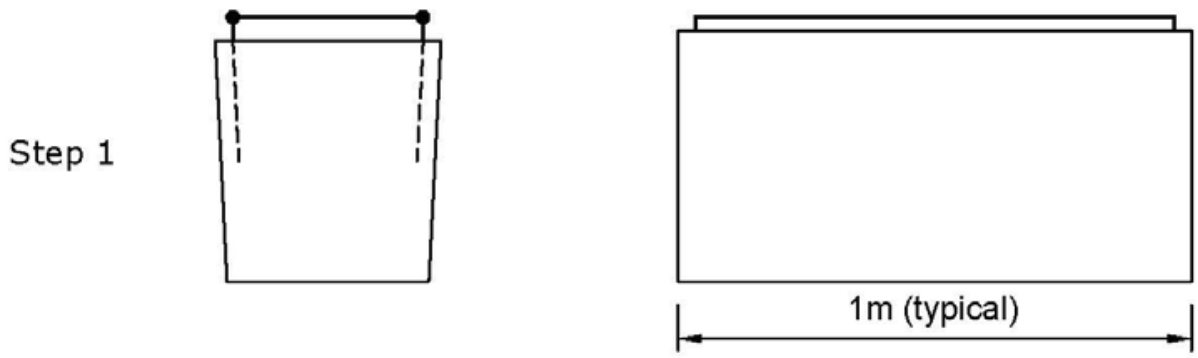

Voussoirs individually precast in accurately manufactured moulds. Minimal Shuttering requirements as all the voussoirs are identical for a circular arch.

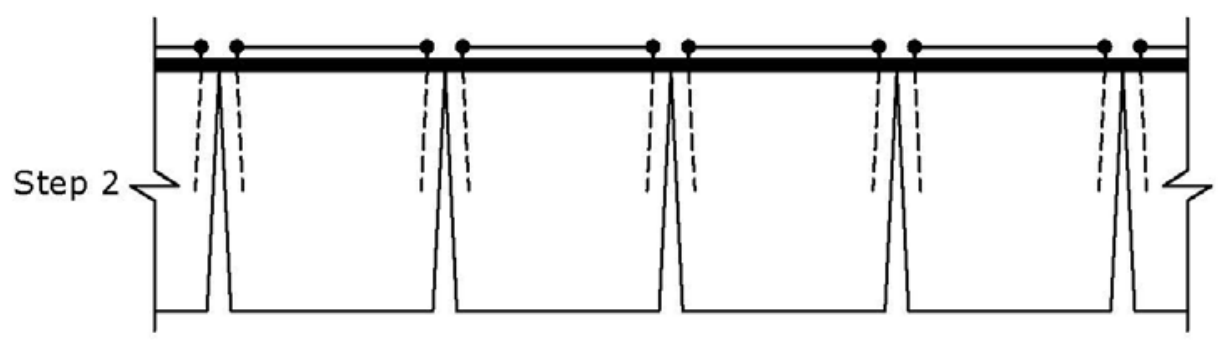

Voussoirs placed on a horizontal line with top edges touching. Polymeric reinforcement stretched along (in contact with) top of voussoirs.

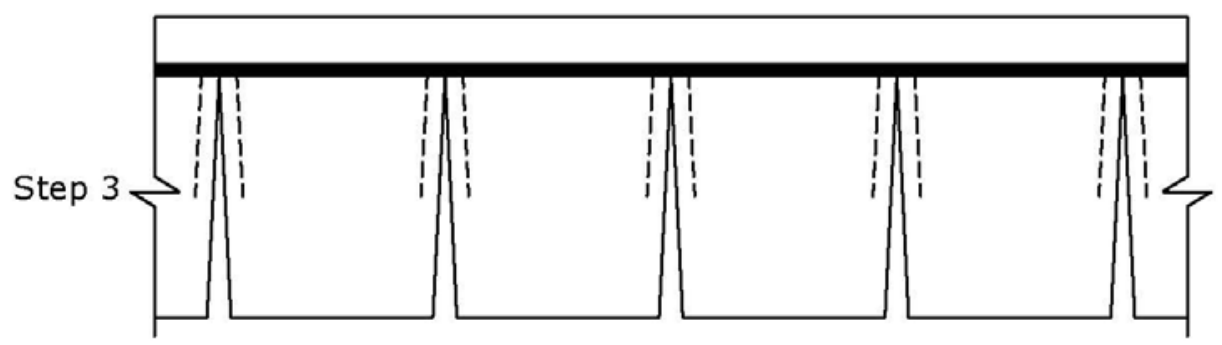

In-situ screeding layer is placed on top and allowed to harden to interconnect the voussoirs and produce a 'FlexiArch' unit ready for lifting.

Fig 1 'FlexiArch method of construction 
The FlexiArch units can be cast in convenient widths to suit the design requirements, site restrictions and available crane capacity. When lifted at the designated anchorage points gravity forces cause the wedge shaped gaps to close. Concrete hinges form in the screed and the integrity of the unit is provided by tension in the polymeric reinforcement and the shear resistance of the screed.

The FlexiArch units are then lifted and placed, in their arched shaped form, on precast footings at the bridge site with all the self-weight then transferred from tension in the polymeric reinforcement to compression in the voussoirs, i.e. it acts in the same way as a conventional masonry arch.

Experience of using this system for over 60 bridges has shown that it has a number of advantages over traditional methods of constructing arches:

- The voussoirs can be accurately, quickly, and consistently produced with the desired taper in relatively simple shuttering.

- High quality concrete can be utilised for the individual precast voussoirs:

- To enhance the durability of the arch whilst in service.

- To greatly reduce the variability in the physical properties normally associated with natural stonework.

\section{Installation of FlexiArch Units}

The primary function of the polymeric reinforcement is to provide sufficient tensile strength so that the FlexiArch units can be lifted safely; both from the flat casting bay on to a flatbed lorry and from the lorry in its designated arch form into position on the precast sill beams at the bridge site. Great care needs to be taken during installation as typically a $1 \mathrm{~m}$ wide 'Flexi Arch' unit for a 15m span bridge can weigh over 10t. However, provided the recommended procedures are adopted it has been found that a typical unit can be accurately located on site every 15 minutes. As a consequence most bridges can be installed in well under a day, thus affording the 'FlexiArch' enormous benefits relative to conventional arch construction.

\section{TEEWELL HILL WIDENING PROJECT}

Teewell Hill masonry arch bridge, with a span of $12.8 \mathrm{~m}$ and a rise of $3 \mathrm{~m}$, carries a two lane single carriageway road and had an adjacent steel footbridge on the west side of the structure.

The bridge is owned by South Gloucestershire Council and had been constructed in the 1840s over the Bristol and Bath railway line (nowadays a popular cycle route) in what is now a busy residential area. The bridge had become an accident blackspot due to the increase in the volume of traffic using the bridge and the inadequate road alignment.

An inspection and assessment had shown the existing masonry arch to be in a good condition and able to sustain SV 80 loading, however the steel pedestrian bridge was in a poor condition and required extensive maintenance and repair.

Following a feasibility study, the preferred option to widen the existing structure was by placing six new FlexiArches, three either side of the original masonry structure widening the bridge by approximately $4 \mathrm{~m}$ on each side. This enabled the road alignment improvements and two new pedestrian footpaths on either side of the bridge. 
The FlexiArch system was chosen over other options as it provided an aesthetically pleasing solution, it's circular profile matched the existing form of the structure. Furthermore the units could be transported to site on flatbed trucks and craned into position relatively quickly, reducing disruption to the public and the prefabricated nature of the system reduced site temporary works.

Conventional masonry arch extensions to each side, if feasible, would have been exceptionally expensive, taken many months to install and the need for centring would have significantly disrupted the National Cycle Route.

One of the crucial design criteria was to ensure construction would accommodate the raked spandrel walls of the existing masonry arch. Therefore Macrete and WSP | Parsons Brinckerhoff decided to explore the possibility of developing bespoke FlexiArch units which would directly fit up against the masonry bridge.

\section{Meeting the Challenge}

The major challenge in this project was addressing the raked spandrel walls and unsymmetrical interface between the new and existing structure. The nature of the existing masonry raked spandrel walls meant that the arch voussoir profile curved in plan Fig 2(a) and (b). The "concave" profile of the arches in plan meant that the crowns on each façade were around $500 \mathrm{~mm}$ inside the plane of the arch footings. Thus the use of standard uniform width FlexiArch units would have left a large gap at the crowns which tapered to zero at the footings of the arch. Using their experience from developing a skew FlexiArch system, Macrete, in collaboration with WSP | Parsons Brickerhoff, designed and manufactured bespoke FlexiArch units, with each voussoir individually tailored to match the exact profile of the existing bridge. This innovation in the FlexiArch meant the design challenge was elegantly solved and eliminated the need for special formwork or cast in-situ joints between the old and new elements thus providing a significant time and cost saving to the client.

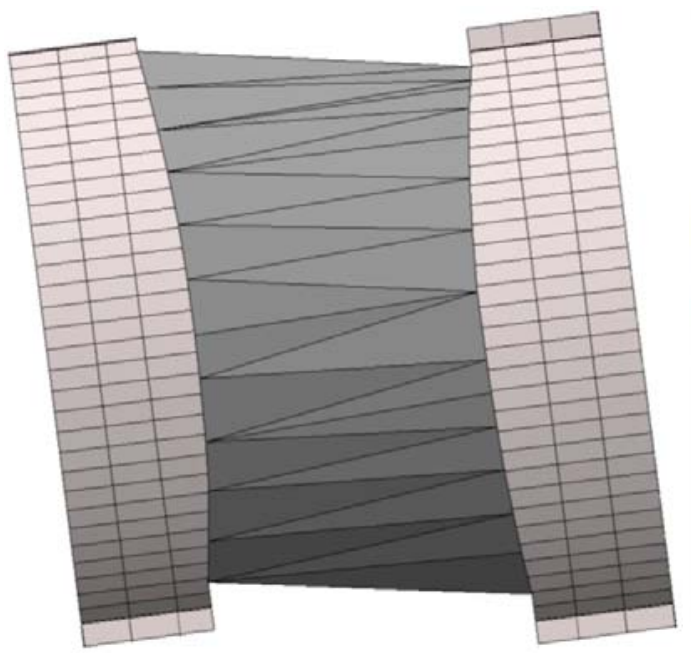

(a) Plan view

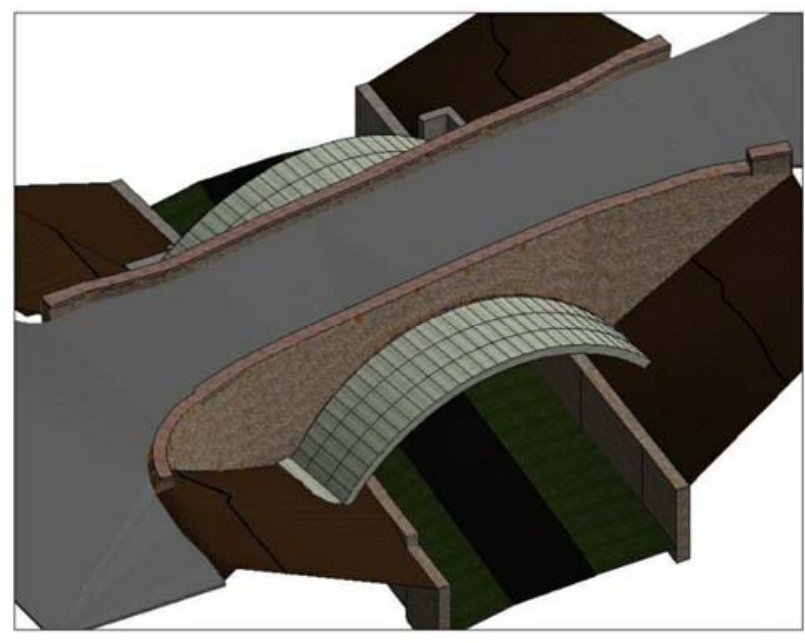

(b) 3D view

Figure 2 Existing Bridge with FlexiArch Extensions

A 3D topographical survey was undertaken at the site which captured the profile of the arch and the complex geometry of the spandrel walls. This information was then processed and used to create a 3D Revit model which in turn was used to develop the bespoke FlexiArch for the required new bridge alignment. 
The unsymmetrical nature of the existing masonry bridge meant that its arches on the east and west elevations were slightly different in profile. Using the Revit model, the design team were able to present the client with two different options regarding the development of a bespoke FlexiArch. The first option consisted of creating two unique FlexiArches (one per side to exactly match) whilst the second option entailed providing one best fit FlexiArch which would accommodate both sides of the bridge. The latter option, which was selected, brought about significant cost savings in manufacturing as only one formwork was required.

Using the Revit model, the custom FlexiArch arch form was optimised to ensure that the difference in levels between the existing arch and new arch soffits would not exceed $30 \mathrm{~mm}$ at any one point, therefore still providing an aesthetically acceptable solution.

Upon completing optimisation of the arch form in elevation, the model was used to accurately determine the plan dimensions of each of the individually tailored voussoirs, for the bespoke FlexiArch units. As the length of the concrete voussoirs varied from around $750 \mathrm{~mm}$ to $1500 \mathrm{~mm}$, Fig (3) polypropylene fibre reinforced concrete was used to ensure that each voussoir had not only the required compressive strength but additional resistance to possible impact damage during the installation process. The structural performance of the FlexiArches under Eurocode bridge loading conditions was designed and checked using analysis software (Obvis 2004).

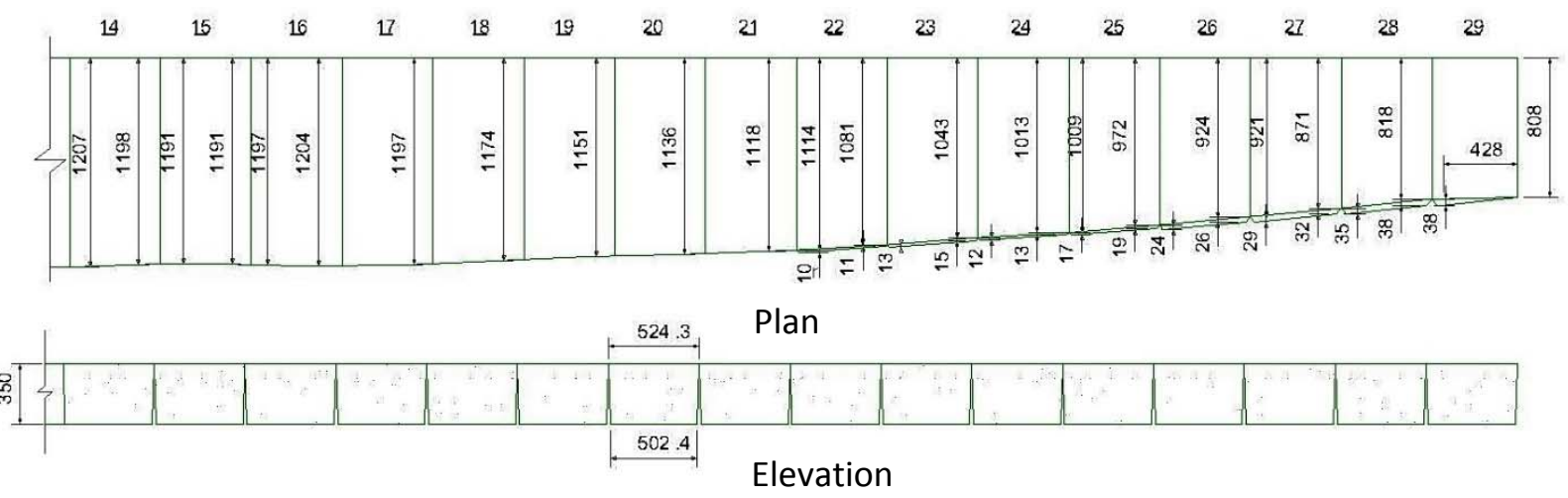

Figure 3 Bespoke FlexiArch units (partial length)

With the development of digital tools it is clear that technology such as digital point cloud laser scanning would considerably speed up the design processes in terms of developing 3D models and increasing levels of accuracy (Fig 4). Such tools would aid the design process and combined with the versatile FlexiArch system, a very cost effective and highly sustainable outcome can be achieved. 


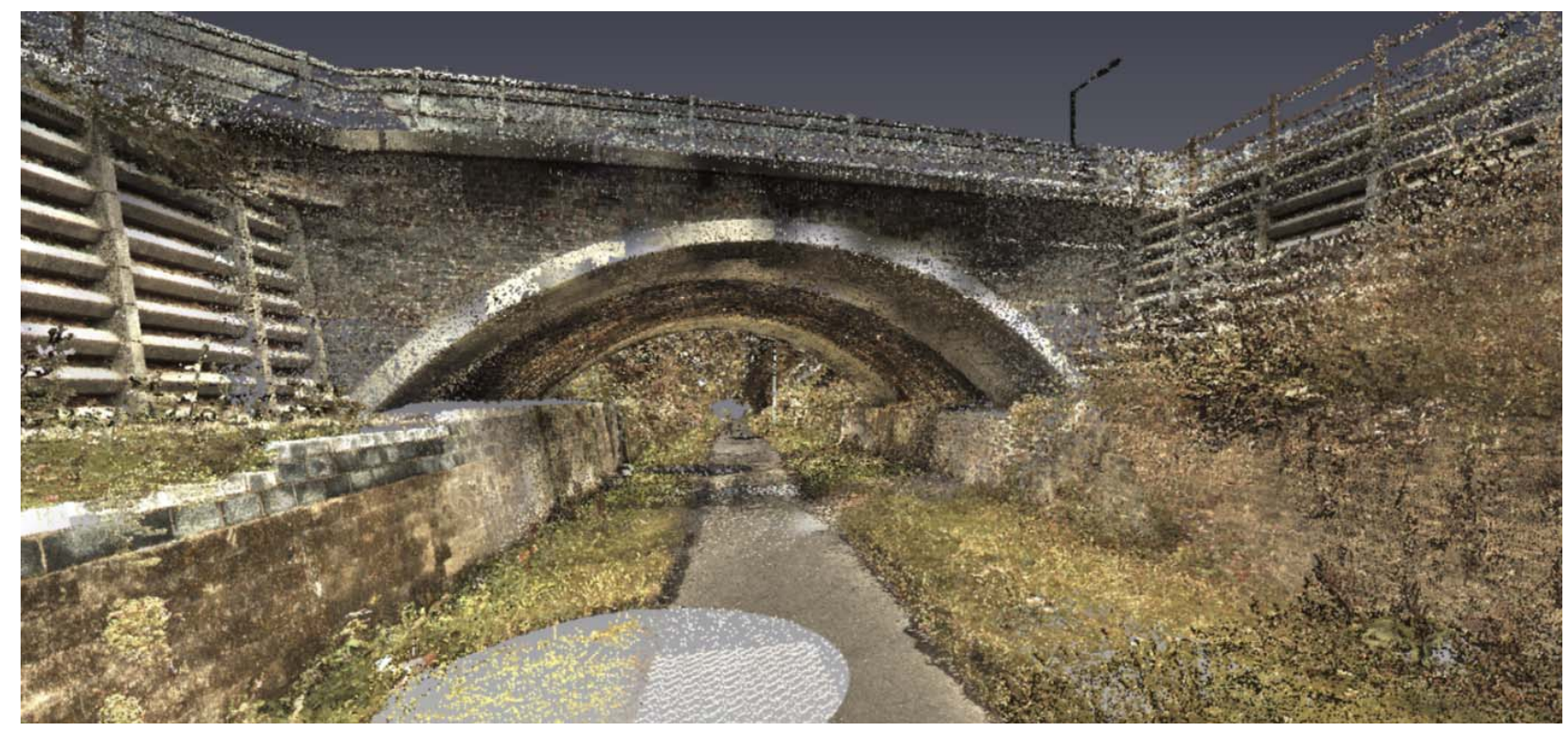

Figure 4 Point cloud laser scan of bridge from cycleway

\section{Installation}

As the bridge site was located in the suburbs of Bristol in a busy residential area, all construction activity had the potential to cause significant inconvenience to local residents. As site access was very limited, road closures were required to carry out any lifting procedures or deliveries. As a result it was crucial that the installation of the units could be carried out in as short a time frame as possible. All precast FlexiArch units arrived flat-pack on the back of lorries and were installed in just a couple of hours, minimising disruption on the cycle path below and the local roads above which were able to be re-opened before peak travel times on the same day.

Extensive previous experience by Macrete in over 60 FlexiArch installations has shown that selfcompacting lean mix concrete backfill speeds up construction and results in greater strength as opposed to the more labour intensive granular backfill which requires compaction. In this particular project unique precast concrete spandrel wall units were designed to follow the road alignment and that of the adjoining embankments, thus eliminating the need for wing walls. The spandrel wall units were also manufactured by Macrete and were supplied with a precast feature corbel which allowed locally sourced stonework to be built on to the units, ensuring a quality pennant sandstone clad finish to keep the structure in keeping with the existing bridge appearance. In this case the client was able to re-create the aesthetics and structural qualities of a masonry arch bridge without requiring costly, time consuming and intrusive centring. The client also benefitted from the speedy installation of the precast units which reduced the cost for crane hire and minimised road closures. Fig 5 shows the sequence of construction. The overall cost of the Teewell Hill Bridge extension project was $f 1.5$ million. 

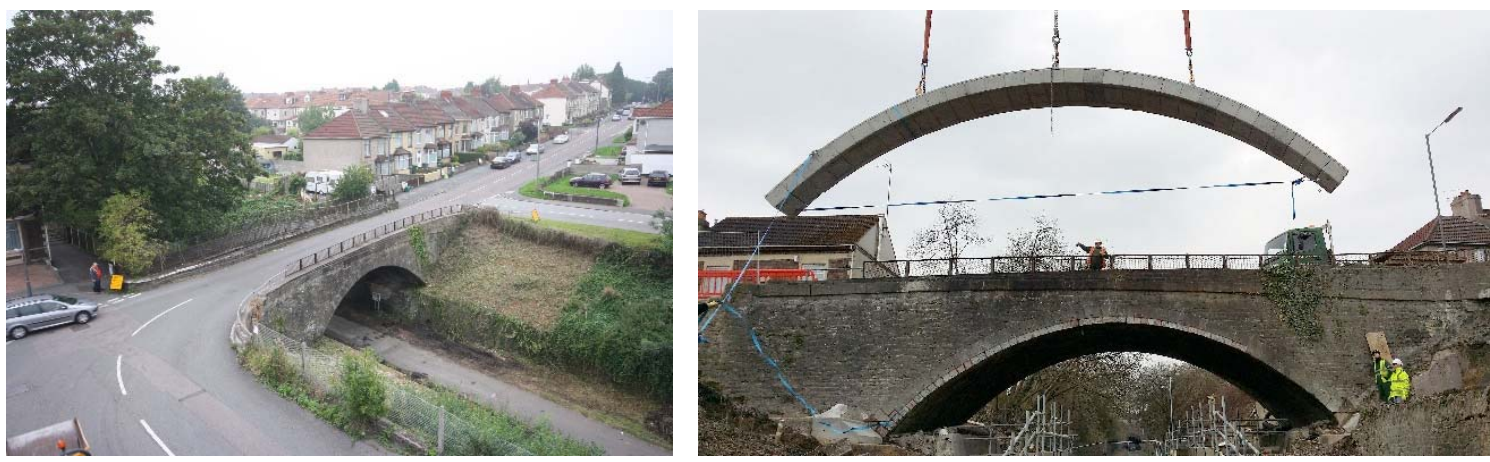

a) Original bridge/junction

b) Lowering first FlexiArch unit into position

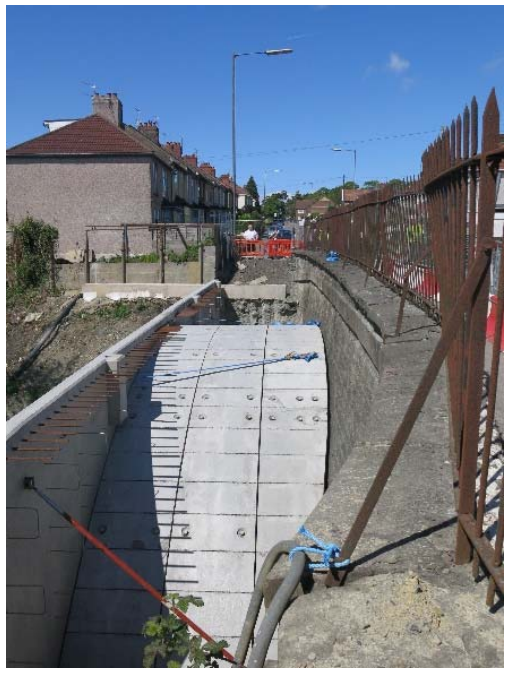

c) Ready for backfilling

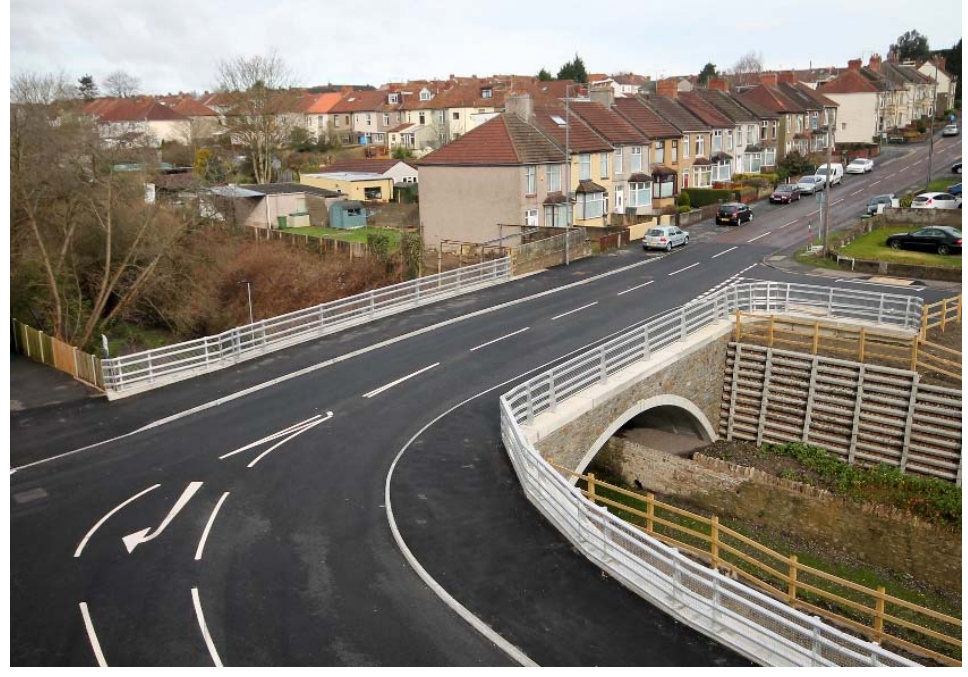

d) Widened bridge/much improved junction

Figure 5 Construction sequence

\section{Sustainability}

The FlexiArch units had no corrodible reinforcement as they act as arches in service and only compressive stresses are generated. As a result, maintenance of the new bridge elements will be minimal, like the original masonry arch bridge. Combining both the old masonry arches and new structural elements, which will not suffer from the effects of reinforcement corrosion, has resulted in a sustainable, long term structural solution. A blended concrete using GGBS was chosen for the precast concrete units, to reduce the overall carbon footprint of the project. Approximately $250 \mathrm{~m}^{3}$ of $\mathrm{C} 6 / 8$ lean mix concrete was used as backfill material up to the level of the crown of the arches. Then a reinforced concrete slab $300 \mathrm{~mm}$ thick was poured on top, using C40/50 concrete to interconnect the existing bridge with the new extensions.

The quick erection of the FlexiArch minimised disruption to the public and the impact on local businesses by keeping closures of the Bristol \& Bath Railway Path (cycle path) and road above to a minimum. 


\section{Concluding Remarks}

The client was searching for an economic and effective solution to their challenging task of widening Teewell Hill bridge. The innovative FlexiArch solution was identified as the preferred option and was adapted so that bespoke variable width units successfully accommodated the complex geometry of the interface with the existing structure. By combining 3D modelling with the versatile FlexiArch system a cost effective and highly sustainable outcome has been achieved, whilst the use of digital tools such as point cloud data scanning would provide further benefit in future projects. Whilst this is the first ever application of this approach the authors are of the view that had the FlexiArch system not been available, alternative solutions would not have resulted in the significant economical, sustainable and programme advantages that benefited this project.

\section{Project Team}

Client: South Gloucestershire Council

Consultant: WSP | Parsons Brinkerhoff

FlexiArch designers and manufacturers: Macrete

\section{Acknowledgements}

The financial support provided by the ICE R\&D Enabling Fund, KTP Scheme, Invest Northern Ireland, DRD Roads Service (NI) and the Leverhulme Trust is gratefully acknowledged. Input by J. Kirkpatrick, D. Robb and I. Hogg is also acknowledged.

\section{References}

HMSO Department of Transport (2004) Design Manual for Roads and Bridges (BD 91/04: Unreinforced masonry arch bridges) [Online] Available at: www.dft.gov.uk/ha/standards/dmrb/vol2/ section2/bd9104.pdf (Accessed: June 2014)

Long A. E. (2004) Concrete arch and method of manufacture, International Patent, Publication 27 May, No. WO 2004/044332A1, Queen's University Belfast

Long A., Kirkpatrick J., Gupta A., Nanukuttan S. and McPolin D. (2013) 'Rapid construction of arch bridges using the innovative FlexiArch', Proc. ICE,Bridge Engineering, 166 (BE3), pp. 143-153

Obvis Ltd. (2007), Archie-Msoftware. http://www.obvis.com 